\title{
Manejo de variedades de soja agroecológica, características agronômicas e
}

\section{produtividade}

\author{
Management of agroecological soy varieties, agronomic characteristics and yield \\ Manejo de variedades agroecológicas de soja, características agronómicas y productividad
}

Recebido: 2610/2021 | Revisado: 05/11/2021 | Aceito: 11/11/2021 | Publicado: 17/11/2021

Edleusa Pereira Seidel

ORCID: https://orcid.org/0000-0001-8821-473X Universidade Estadual do Oeste do Paraná, Brasil

E-mail: edleusa.seidel@unioeste.br

Emerson Fey

ORCID: https://orcid.org/0000-0002-8348-181X Universidade Estadual do Oeste do Paraná, Brasil

E-mail: emerson.fey@unioeste.br

Neumárcio Vila Nova da Costa

ORCID: https://orcid.org/0000-0003-2576-7470

Universidade Estadual do Oeste do Paraná, Brasil

E-mail: neumarciovc@ hotmail.com

Vanda Pietrowski

ORCID: https://orcid.org/0000-0003-3276-4980

Universidade Estadual do Oeste do Paraná, Brasil

E-mail: vandapietrowski@gmail.com

Leidiane Coelho Carvalho

ORCID: https://orcid.org/0000-0003-3768-7910

Universidade Estadual do Oeste do Paraná, Brasil

E-mail: leidiane.ccarvalhoo@gmail.com

Diandro Ricardo Barilli

ORCID: https://orcid.org/0000-0001-9311-7408

Universidade Estadual do Oeste do Paraná, Brasil

E-mail: diandro23@hotmail.com

\begin{abstract}
Resumo
A procura por grãos agroecológicos vem aumentando e isto, gera uma demanda por variedades adaptadas as regiões produtoras destes grãos. Desta forma, o presente estudo teve por objetivo avaliar as características agronômicas, a produtividade de variedades de soja agroecológico no ano agrícola 2020/2021; bem como, apresentar os relatos dos manejos de fertilidade, controle de plantas espontâneas, pragas e doenças destas variedades. As diferentes variedades foram cultivadas em um Latossolo Vermelho Eutroférrico. Avaliou-se a altura de plantas, diâmetro de caule, altura de inserção da primeira vagem, número de nós, número total de vagem, grãos totais por planta, população de plantas, peso de mil grãos, índice de plantas acamadas e produtividade. Após a colheita avaliou-se umidade dos grãos o número e área de danos causados por percevejos. As variedades que tiveram maior produtividade foram: BRS 525 cultivada nos dois talhões e a BRS 539, BRS 391 e a BR 166013 cultivadas no talhão Kathounian com produtividade média de $3178 \mathrm{~kg} \mathrm{ha}^{-1}$. Entretanto, os grãos colhidos apresentam muitos danos causados percevejos o que reduz a qualidade dos mesmos. Os resultados demonstram que o manejo adotado para o cultivo de soja agroecológico está adequado, mas necessita melhorias como o manejo de percevejos e que a estes resultados têm grande relevância para a escolha dos cultivares de soja a serem cultivados em sistema agroecológicos na região.
\end{abstract}

Palavras-chave: Cultivo orgânico; Glycine max; Plantio direto de grãos; Agricultura sustentável.

\section{Abstract}

The demand for agroecological grains is increasing and this generates a demand for adapted varieties as producing regions of these grains. Thus, this study aimed to evaluate the agronomic characteristics, the productivity of agroecological soybean varieties in the agricultural year 2020/2021; as well as presenting reports on fertility management, spontaneous plant control, pests and diseases of these varieties. The different varieties were cultivated in a Eutroferric Red Latosol. Record the plant height, stem diameter, height of insertion of the first pod, number of nodes, total number of pods, total grains per plant, plant population, weight of a thousand grains, bed plant index and yield. After harvesting, the number and area of damage caused by stink bugs were evaluated. The varieties with the highest productivity were: BRS 525 cultivated in the two stands and BRS 539, BRS 391 and BR 166013 cultivated in the Kathounian stand with an average yield of $3178 \mathrm{~kg}$ ha-1. However, the harvested grains present a lot of damage caused by the bugs, which reduces their quality. The results demonstrate that the management adopted for agroecological soybean cultivation is adequate, but update improvements such as the management of stink bugs and 
that these results are in great demand for the choice of soybean cultivars to be cultivated in an agroecological system in the region.

Keywords: Organic cultivation; Glycine max; No-tillage of grains; Sustainable agriculture.

\begin{abstract}
Resumen
La demanda de granos agroecológicos está aumentando y esto genera una demanda de variedades adaptadas como regiones productoras de estos granos. Así, este estudio tuvo como objetivo evaluar las características agronómicas, la productividad de variedades agroecológicas de soja en el año agrícola 2020/2021; así como presentar informes sobre manejo de fertilidad, control espontáneo de plantas, plagas y enfermedades de estas variedades. Las diferentes variedades se cultivaron en un Latosol Rojo Eutroférrico. Registre la altura de la planta, el diámetro del tallo, la altura de inserción de la primera vaina, el número de nudos, el número total de vainas, el total de granos por planta, la población de plantas, el peso de mil granos, el índice de plantas de lecho y el rendimiento. Después de la cosecha, se evaluó el número y el área de daño causado por las chinches. Las variedades con mayor productividad fueron: BRS 525 cultivadas en los dos rodales y BRS 539, BRS 391 y BR 166013 cultivadas en el rodal de Kathounian con un rendimiento promedio de $3178 \mathrm{~kg}$ ha-1. Sin embargo, los granos recolectados presentan mucho daño causado por los insectos, lo que reduce su calidad. Los resultados demuestran que el manejo adoptado para el cultivo de soja agroecológica es adecuado, pero actualizan mejoras como el manejo de chinches y que estos resultados son de gran demanda para la elección de cultivares de soja para ser cultivados en un sistema agroecológico en la región.

Palabras clave: Cultivo orgánico; Glycine max; Labranza cero de granos; Agricultura sostenible.
\end{abstract}

\title{
1. Introdução
}

A demanda mundial por proteína de soja é crescente, seja para uso na produção de proteína animal ou como insumo na produção de alimentos ou na produção de proteína animal é cada vez maior. Aliado a isso, os consumidores finais estão em busca de produtos oriundos de uma agricultura social e ambientalmente mais sustentável. Assim, a agricultura orgânica surge em um momento onde a preocupação com a degradação ambiental, a busca por saúde, qualidade de vida e a melhoria da renda dos pequenos produtores rurais passam a ser discutidas pela sociedade (Inagaki et al., 2018).

De acordo com Azadi et al. (2011) na agricultura orgânica produz-se um alimento mais saudável e ainda se mantem o ecossistema equilibrado com o mínimo de impacto negativo. Nesse sistema há o incentivo de produção local e a disponibilidade de alimentos mais próximas do consumidor.

Nesse cenário o mercado de produtos orgânicos ganha destaque. Este produto apresenta preços superiores em comparação com a soja convencional, o que gera bons resultados ao produtor, sendo um bom investimento para pequenos produtores (Deser,2008; Embrapa, 2015). No entanto, segundo McBride e Greene, (2009) os aumentos nos preços da soja convencional e nos preços do combustível reduzem o incentivo para o plantio de soja orgânica, pois melhoram os retornos da produção convencional e aumentam os custos relativos da produção orgânica.

O que é corroborado por Uematsu e Mishra (2012) que afirmam que os agricultores orgânicos certificados não tem uma renda familiar significativamente maior do que os agricultores convencionais, mesmo tendo uma receita maior. Entretanto, seus custos com mão de obra, seguro e despesas de marketing são elevados. Estes custos podem ser ainda maiores, se antes de produzir grãos orgânicos o produtor não produzia grãos convencionais. Isso porque para a produção de soja orgânica há necessidade de se ter um bom parque de máquinas (trator, semeadora, pulverizador e espalhador de esterco); ou então, fazer parte de uma associação que disponibiliza tais equipamentos. Outro fator importante é uma boa assistência técnica.

A falta de incentivos econômicos pode ser uma barreira importante para a conversão para a agricultura orgânica.

Alguns trabalhos evidenciam algumas dificuldades na produção de grãos orgânicos tais como: a fertilidade (Aidar \& Kluthcouski 2009; Pereira et al.,2015), controle de pragas e doenças (Inagaki, 2018; Simonetti \& Perond, 2018; Zorzzi et al., 2021), controle de plantas daninhas (Fontanetti, et al. 2006, Brighent \& Brighent, 2009), falta pesquisa para criação de novas cultivares e variedades para o cultivo orgânico (Simonetti \& Perondi, 2019); bem como a falta de crédito agrícola específico para este sistema de produção (Darold, 2000) para investir, principalmente em maquinários. Inagaki et al. (2018) em sua pesquisa indicam a inviabilidade de produção da soja orgânica na região Oeste do Paraná, determinada principalmente por três 
fatores: a falta de pesquisas voltadas para atividade, as dificuldades no manejo da produção e a baixa demanda da população brasileira por produtos orgânicos. Enquanto para Sacco, et al. (2015) a adoção de sistemas orgânicos de produção enfrenta desafios associados à produtividade mais baixas do que em sistemas convencionais.

Desta forma, o presente estudo teve por objetivo avaliar as características agronômicas, a produtividade de variedades de soja em sistema agroecológico no ano agrícola 2020/2021; bem como, apresentar e discutir os manejos de fertilidade, o controle de plantas espontâneas, pragas e doenças durante seu cultivo.

\section{Metodologia}

Para elaboração do presente trabalho utilizou-se duas metodologias. A primeira está pautada na construção, e na sistematização das experiências da equipe do Centro Vocacional Tecnológico de Agroecologia, Mandioca e Agricultura Sustentável do Oeste do Paraná no cultivo de soja Agroecológica. Este relato foi pautado nos 10 anos de experiência do grupo no cultivo de grãos. Foram relatados os principais manejos adotados; bem como os insumos utilizados.

A segunda metodologia foi de pesquisa científica de um experimento com cultivares de soja. Para realizar essa pesquisa utilizou-se um delineamento em faixa com cinco repetições onde avaliou-se 8 cultivares de soja cultivadas no sistema agroecológico.

\subsection{Descrição da área e condições meteorológicas durante a condução do cultivo}

A área está localizada no município de Entre Rios do Oeste - PR, no Centro de Vocacional Tecnológico de Agroecologia, Mandioca e Agricultura Sustentável do Oeste do Paraná, sob altitude de $521 \mathrm{~m}$ e coordenadas geográficas $24^{\circ} 40^{\prime} 54^{\prime \prime} \mathrm{S}$ e $54^{\circ} 17^{\prime} 3^{\prime \prime}$ O (Figura 1). O solo é classificado como Latossolo Vermelho Eutroférrico típico de acordo com Sistema Brasileiro de Classificação de Solos (Santos et al., 2015).

O clima segundo classificação climática de Koppen é tipo Cfa, subtropical úmido mesotérmico de verões quentes com temperatura média acima de $22^{\circ} \mathrm{C}$ e tendências de concentração de chuvas, o inverno com geadas pouco frequentes e temperatura inferior a $18^{\circ} \mathrm{C}$. A precipitação média anual é de 1.600 a $1.800 \mathrm{~mm}$ (Caviglione et al., 2000). Na Figura 2 são apresentadas as a precipitação média entre os meses de março de 2019 e abril de 2020 e as temperaturas mínimas e máximas durante o desenvolvimento da cultura.

Figura 1: Localização da área experimental no município de Entre Rios/PR.
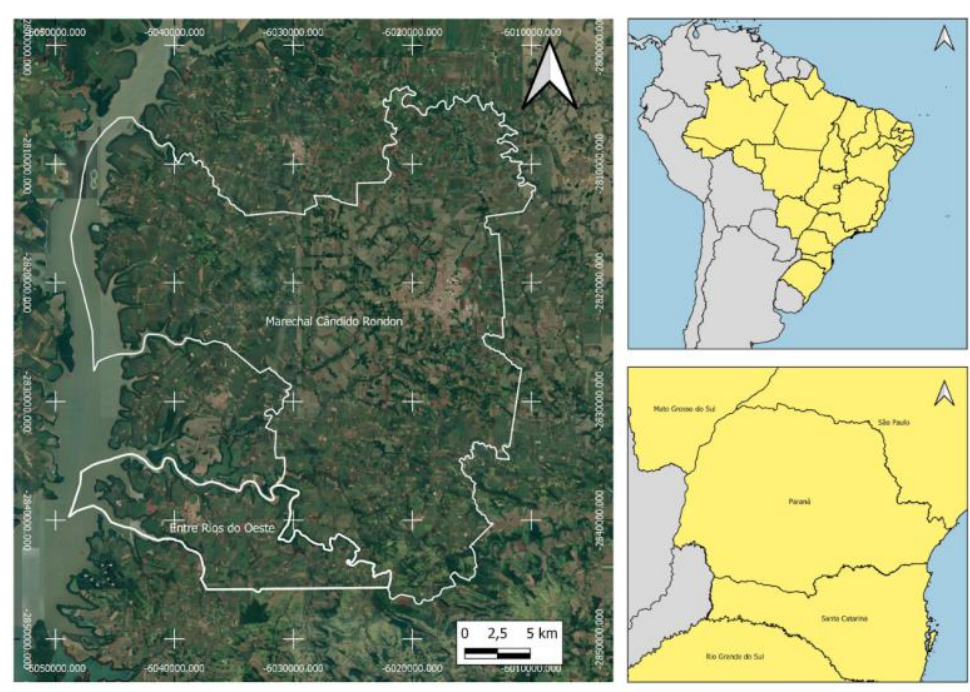

Fonte: Autores. 
Figura 2: Precipitação média, temperatura mínima e máxima durante o desenvolvimento da cultura entre os meses de março de 2019 a abril de 2020 na unidade experimental Professor Luís Orlando Alcebíades em Entre Rios do Oeste.

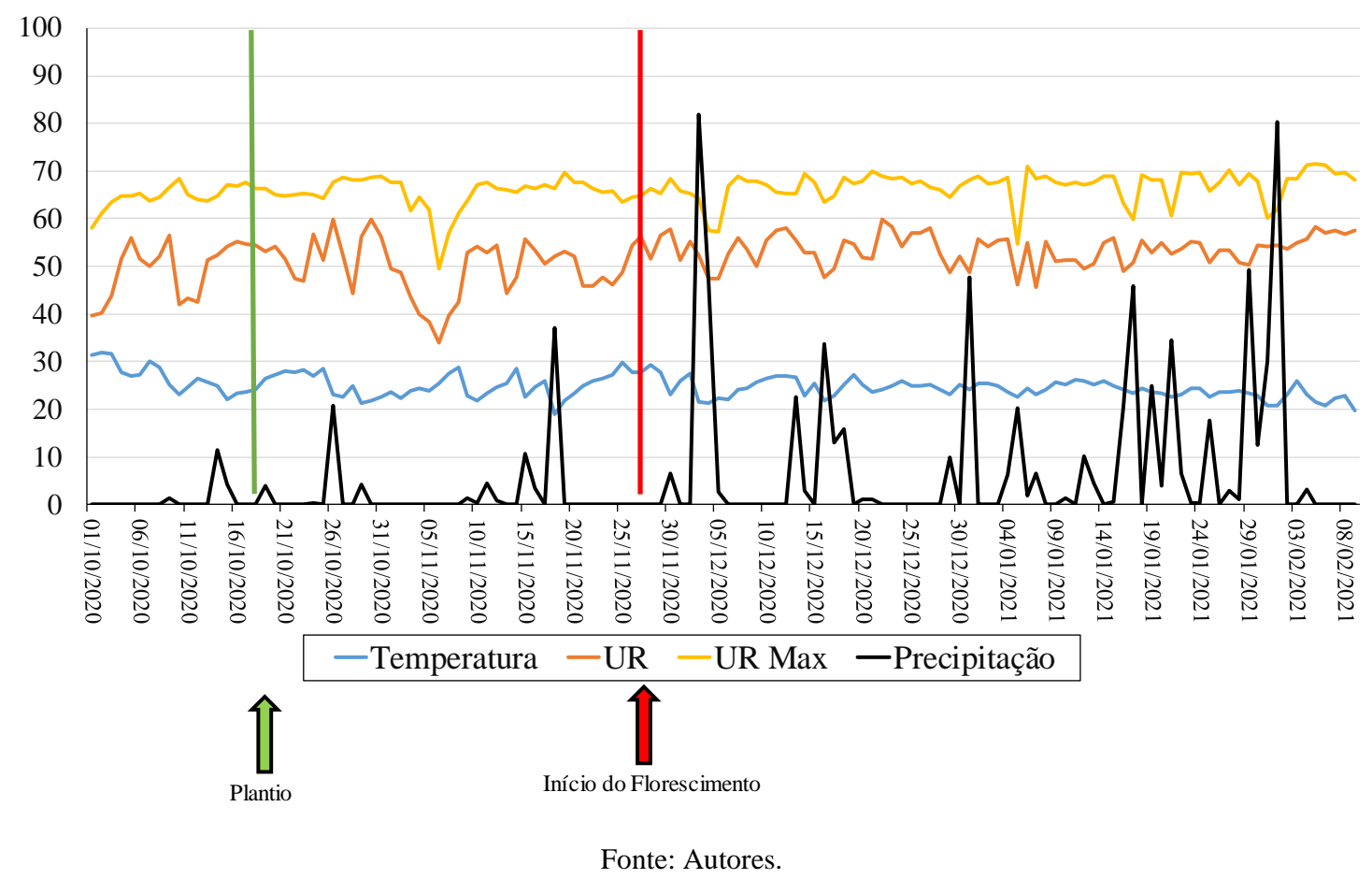

\subsection{Histórico do manejo de fertilidade adotado, manutenção da fertilidade e semeadura}

A área vem sendo cultivada no sistema de plantio direto e periodicamente é realizado análises químicas. Os resultados da última análise química foram: $\mathrm{MO}: 26,26 \mathrm{~g} \mathrm{dm}^{-3} ; \mathrm{pH} \mathrm{CaCl}_{2}: 5,40 ; \mathrm{P}: 97.29 \mathrm{mg} \mathrm{dm}^{-3} ; \mathrm{K}, \mathrm{Ca}, \mathrm{Mg}: 0,79 ; 6,09 \mathrm{cmol}_{\mathrm{c}} \mathrm{dm}^{-3} \mathrm{e}$ 2,27 respectivamente. Saturação de bases: 74\%. Mn, Cu e Zn: 87,12; 10,46 e 4,80 mg dm ${ }^{-3}$ respectivamente. Os extratores foram: extrator Mehlich: P, K, Mn, $\mathrm{Cu}$ e Zn; extrator $\mathrm{KCl}$ : Ca, $\mathrm{Mg}$ e Al; extrator dicromato de sódio: $\mathrm{MO}$

No ano de 2018 foi aplicado em toda a área $900 \mathrm{~kg} \mathrm{ha}^{-1}$ de fosfato natural reativo. Neste ano as culturas de milho, soja e feijão receberam também a aplicação do fertilizante supermagro na dose de $5 \%$ do volume de calda. Aplicou-se também ecozil na dose de $0,5 \mathrm{~kg} \mathrm{ha}^{-1}$ volume de calda $(180 \mathrm{~L})$. No mês de setembro de 2019 em toda área foi aplicada $2,5 \mathrm{t}$ ha ${ }^{-1}$ de pó de rocha de basalto. $\mathrm{Na}$ análise do pó de rocha este apresentou os seguintes teores: $\mathrm{SiO}_{2}=51,17 \%, \mathrm{Al}_{2} \mathrm{O}_{3}=12,65 \%, \mathrm{Fe}_{2} \mathrm{O}_{3}=$ $14,24, \mathrm{CaO}=9,73 \% \mathrm{MgO}=5,21 \%$ e $\mathrm{K}_{2} \mathrm{O}=1,01 \%$.

A área foi dividida em dois talhões, o primeiro talhão denominado Hahnemann com área de 1,55 hectares e o segundo talhão denominado Kathonian com área de 1,4 hectares. Na entressafra de 2020 no talhão Hahnemann foi cultivado plantas de cobertura do Mix-520 (nabo forrageiro + aveia branca + centeio), no talhão Kathonian foi cultivado aveia branca para produção de grãos. No início de setembro as plantas de cobertura foram manejadas e a aveia colhida, em seguida foi aplicado 8 t ha $\mathrm{a}^{-1}$ de cama de frango.

No dia 18 de outubro de 2020 foi realizada mecanicamente em sistema de plantio direto a semeadura da soja. Previamente as sementes de soja foram tratadas com microrganismos (Bradyrizobium) e com bacillus thuringiensis. O espaçamento entre linhas adotado foi de $0,5 \mathrm{~m}$ para todas as cultivares. Aplicou-se $437 \mathrm{~kg} \mathrm{ha}^{-1}$ do adubo yoorin no sulco de semeadura. 


\subsection{Descrição dos cultivares e população de plantas}

$\mathrm{Na}$ Tabela 1 são apresentadas as cultivares de soja semeadas, seu ciclo, porcentagem de germinação e densidade de semeadura. A variedade BR 166013 e BRS 539 apresentaram baixa germinação com 48\% e 40\%, respectivamente; por isso, optou-se por aumentar o número de sementes por metro linear. No talhão denominado Hahnemann com área de 1,55 hectares foram semeadas duas cultivares: BRS 525 e DF 2353. No talhão 2 denominado Kathonian com área de 1,4 hectares foram semeados oito cultivares/linhagens.

Tabela 1: Cultivar/Linhagem, ciclo, porcentagem de germinação e número de sementes semeadas por metro linear- safra 2020/2021

\begin{tabular}{cccc}
\hline Cultivar/linhagem & Ciclo & Germinação(\%) & $\mathrm{N}^{\circ}$ sementes/m linear \\
\hline BRS 391 & 6.4 & 86,0 & 18 \\
BRS 511 & 6.4 & 86,5 & 18 \\
BRS 284 & 6.3 & 94,0 & 16 \\
BR 16 6013 & 6.0 & 48,0 & 30 \\
BRS 525 & 5.6 & 86,0 & 18 \\
DF 2353 & 5.6 & 91,5 & 20 \\
GE-02 & 6.0 & 86,5 & 20 \\
BRS 539 & 5.8 & 40,0 & 30 \\
\hline
\end{tabular}

Fonte: Autores.

\subsection{Controle de plantas espontâneas}

Os talhões onde foi cultivado a soja (Kathounian e Hahnemann) apresentaram manejos diferentes antecedendo a cultura da soja. Portanto, no levantamento fitossociológico foram observados diferentes espécies e ocorrências de plantas espontâneas. No talhão Kathounian a cultura antecessora foi a aveia branca que apresentou um rápido fechamento de linha e, durante seu desenvolvimento apresentou poucas plantas espontâneas. A colheita da aveia foi realizada no dia 14 de setembro de 2020 e resultou em um acumulo de $3725 \mathrm{t} \mathrm{ha}^{-1}$ de massa seca de palhada. Após a colheita da aveia foi feito o manejo da área com o rolo faca. Em decorrência de condições climáticas desfavoráveis a semeadura da soja ocorreu cerca de um mês após a colheita da aveia, o que refletiu na presença de algumas manchas de caruru (Amaranthus retroflexus) na área.

Após a colheita da aveia foi feito o manejo da área com o rolo faca. Neste talhão, a semeadura de soja foi feita no dia 18 de outubro de 2020, já com a presença de algumas manchas de caruru (Amaranthus retroflexus) na área.

No talhão Hahnemann a cultura antecessora foi um mix de cobertura (nabo forrageiro + aveia branca + centeio). Esse mix teve algumas falhas de germinação e forte pressão de formigas cortadeiras. Nessas condições, a produção de massa seca aportada ao solo foi menor do que o da aveia, ficando em $3460 \mathrm{t} \mathrm{ha}^{-1} \mathrm{o}$ que resultou em uma grande incidência de plantas espontâneas.

O manejo do mix cultivado no talhão Hahnemann foi realizado no dia 14 de setembro de 2020 com o rolo faca. Este manejo foi realizado tardiamente quando o nabo já havia produzido sementes. Como resultado houve uma grande germinação de nabo na cultura da soja; bem como, por guanxuma (Sida spp.). A semeadura de soja nesse talhão foi feita no mesmo dia em que foi realizada no talhão Kathounian. Foram observadas nos dois talhões uma ocorrência significativa de capim colonião (Panicum maximum) e trapoeraba (Commelina benghalensis); além de outras espécies, no entanto em menor proporção.

Outra técnica adotada nos dois talhões para a redução das plantas espontâneas foi a capina mecânica realizada por equipamento automatizado. Esse sistema de capina é importante neste sistema de produção, pois é rápida e requer menor mão de obra. Foram realizadas duas capinas mecanizadas uma realizada entre os dias 05 e 07 de novembro quando a soja estava no estádio V2 e outra, no dia 26 de novembro. 
Quando a soja estava no estádio R1 foi realizada a capina manual dos talhões visando o controle das plantas que germinaram nas linhas da cultura e das plantas que emergiram após a capina mecânica. Nesta capina retirou-se principalmente capim colonião, lab-lab e guanxuma principalmente nas linhas de plantio.

Durante o desenvolvimento cultura da soja foram realizados periodicamente levantamentos fitossociológico das plantas espontâneas (Quadro 1). Foram identificadas 20 espécies de plantas espontâneas, as quais foram atribuídas a 11 famílias. A família que apresentou mais representativa foi a Poaceae; com um total de 5 espécies, seguida pela Amanthaceae (2) Asteraceae (2) e a Lamiaceae (2) (Quadro 1).

É possível notar também que no talhão Hahnemann, onde havia mandioca antecedendo o mix de plantas (aveia branca + centeio + nabo forrageiro) apresentou mais espécies de plantas espontâneas em relação ao khathounian, que tinha lab-lab, seguindo pelo cultivo da aveia branca.

Quadro 1: Levantamento fitossociológico de plantas espontâneas nos dois talhões com soja cultivadas em sistema agroecológico.

\begin{tabular}{|c|c|c|c|c|}
\hline Família & Espécie & Nome Comum & talhão Kathounian & talhão Hahnemann \\
\hline Amanthaceae & Alternantera Tenella & Apaga fogo & $\mathrm{x}$ & $\mathrm{x}$ \\
\hline Amanthaceae & Amaranthus retroflexus & Caruru & $\mathrm{x}$ & \\
\hline Asteraceae & Bidens subalternans & Picão Preto & $\mathrm{x}$ & $\mathrm{x}$ \\
\hline Asteraceae & Galinsoga Parviflora & Picão Branco & $\mathrm{x}$ & $\mathrm{x}$ \\
\hline Brasicaceae & Raphanus raphanistrum & Nabiça & $\mathrm{x}$ & $\mathrm{x}$ \\
\hline Commelinaceae & Commelina benghalensis & Trapoeraba & $\mathrm{x}$ & $\mathrm{x}$ \\
\hline Convulvolaceae & Ipomea triloba & Cipó corda de Viola & $\mathrm{x}$ & $\mathrm{x}$ \\
\hline Euphorbiaceae & Euphorbia Heterophylla & Amendoim Bravo & $\mathrm{x}$ & $\mathrm{x}$ \\
\hline Lamiaceae & Leonurus sibiricus & Rubim & $\mathrm{x}$ & $\mathrm{x}$ \\
\hline Lamiaceae & Mesosphaerum suaveolens & Salva Limão & & $\mathrm{x}$ \\
\hline Malvaceae & Sida Spp. & Guanxuma & $\mathrm{x}$ & $\mathrm{x}$ \\
\hline Marantaceae & Maranta sobolifera & Caeté & & $\mathrm{x}$ \\
\hline Poaceae & Avena sativa & Aveia & $\mathrm{x}$ & $\mathrm{x}$ \\
\hline Poaceae & Brachiaria plantaginea & Capim marmelada & & $\mathrm{x}$ \\
\hline Poaceae & Digitaria horizontalis & Capim colchão & $\mathrm{x}$ & $\mathrm{x}$ \\
\hline Poaceae & Digitaria Insularis & Capim Amargoso & & $\mathrm{x}$ \\
\hline Poaceae & Eulesine indica & Capim pé de Galinha & & $\mathrm{x}$ \\
\hline Poaceae & Panicum maximum & Capim Colonião & & $\mathrm{x}$ \\
\hline Rubiaceae & Richardia Brasiliensis & Poaia Branca & $\mathrm{x}$ & $\mathrm{x}$ \\
\hline
\end{tabular}

Fonte: Autores.

\subsection{Controle de pragas e doenças}

As pragas foram monitoradas semanalmente, utilizando pano de batida conforme metodologia da Embrapa (CorrêaFerreira, 2012). As principais pragas observadas foram: Besouro verde metálico, Maecolaspis spp. (Coleoptera: Chrysomelidae), lagarta da soja, Anticarsia gemmatalis Hübner, 1818 (Lepidoptera: Erebidae), lagarta falsa-medideira, Chrysodeixis includens (Walker, 1858), lagarta preta, Spodoptera cosmioides (Walker, 1858), lagarta-das-vargens Spodoptera eridania (Cramer, 1782) (Lepidoptera: Noctuidae) e percevejo marrom, Euschistus heros (Fabricius, 1798) (Hemiptera: Pentatomidae).

Na Figura 3 são apresentadas a época e o número médio de lagartas por pano de batida; bem como, o produto adotado para seu controle. Apesar de não ter atingido o nível de dano econômico para lagartas (20 lagartas por pano de batida), a cultura apresentou desfolha por ocorrência do besouro verde metálico. Em virtude de não existir manejo recomendado em 
cultivos agroecológicos para este inseto, foi optado pela aplicação de Bacillus thuringiensis (500 $\mathrm{g} \mathrm{ha}^{-1}$ ) no dia 23 de dezembro de 2020 para o manejo de A. gemmatalis e C. includens no talhão Hahnemann, e com isto contribuir para diminuir a desfolha na cultura.

No mês de janeiro houve alta precipitação e alta umidade relativa do ar, o que resultou na ocorrência natural do fungo etnomopatogênico Metarhizium rileyi em lagartas de A. gemmatalis e C. includens, porém foi observado baixa incidência nas lagartas de S. cosmioides, por esse motivo optou-se pela aplicação de Tracer $\left(50 \mathrm{~mL} \mathrm{ha}^{-1}\right)$ no dia 19 de janeiro de 2021 para o controle dessas lagartas, visto que sua população estava alta e poderia ocasionar danos nas vagens e grãos de soja.

Para auxiliar no manejo de percevejo marrom, foram instaladas armadilhas iscas em garrafas pet de $2 \mathrm{~L}$ com aberturas no terço médio do recipiente, contendo solução de urina bovina + sal de cozinha (cloreto de sódio), nas proporções de $3 \mathrm{~L}$ de urina e $500 \mathrm{~g}$ de sal, dissolvidos em $7 \mathrm{~L}$ de água (EMBRAPA, 2014). A solução era adicionada a garrafa a um nível máximo de $2 \mathrm{~cm}$ abaixo das aberturas. No total foram instaladas 25 armadilhas na área. Para o manejo de doenças foi aplicado oxicloreto de cobre $\left(750 \mathrm{~mL} \mathrm{ha}^{-1}\right)$ em ambos os talhões.

Figura 3: Número médio de lagartas por pano de batida nos diferentes talhões e aplicações realizadas para o controle dessa praga na cultura de soja agroecológica.

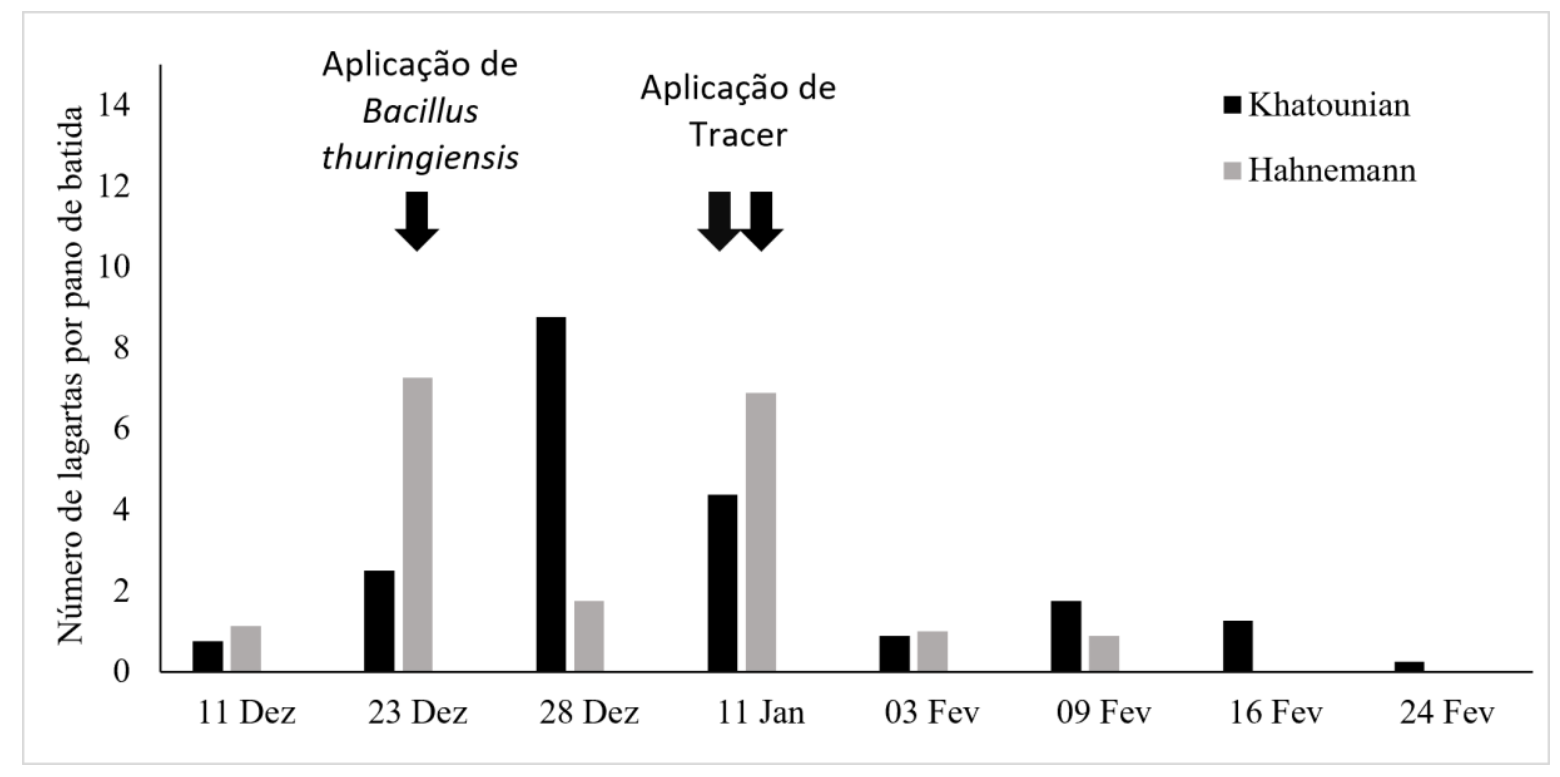

Fonte: Autores.

\subsection{Avaliações dos componentes agronômicos, produtividade da soja e danos por percevejo nos grãos de soja}

Para cada variedade semeada no Khatounian e no Hahnemann foram avaliadas 5 parcelas. As avaliações dos componentes agronômicos foram realizadas em fase de plena maturação (estádio R8), sendo coletadas dez plantas de cada parcela. A população final de plantas foi avaliada contando-se o número de plantas em 10 metros, sendo que cada parcela com 10 repetições. Após, o resultado convertido em plantas por hectare.

A altura média das plantas e a inserção da primeira vagem foi realizada com o auxílio de uma régua graduada em centímetros, mediu-se a distância do colo da planta à extremidade apical da haste principal e do colo da planta à inserção da primeira vagem, respectivamente. $\mathrm{O}$ diâmetro de caule foi realizado com um paquímetro.

A avaliação da massa de mil grãos foi realizada conforme prescrições estabelecidas pelas regras para análise de sementes (Brasil, 2009). Coletou-se oito sub-amostras de 100 grãos cujas massas foram determinadas em balança de precisão. 
A produtividade foi obtida colhendo parcelas 5 de 10 × 6 m no talhão Khatounian e de 15 x 6 m no Hahnemann, com isso foi estimado a produtividade em quilos por hectare, corrigindo o teor de água para $13 \%$.

Para avaliar os danos de percevejos em sementes de soja foi utilizado o teste de tetrazólio. Este método é rápido e com boa precisão. $\mathrm{O}$ teste de tretrazólio foi realizado com 4 repetições de 25 sementes e essas foram colocadas entre papel toalha e umedecidas com água destilada por 16 horas e acondicionada em BOD a $25{ }^{\circ} \mathrm{C}$. Após este prazo foram transferidas para um bequer de $50 \mathrm{~mL}$ e adicionou uma solução aquosa de 2,35 trifenil cloreto de tetrazólio $(0,075 \%)$. Em seguida foram acondicionadas em câmara de envelhecimento acelerado a $42{ }^{\circ} \mathrm{C}$ por três horas para obter coloração uniforme dos grãos. Retirou-se da estufa e lavou-se com água destilada e em seguida procedeu-se a avaliação, conforme descrito por França Neto; Krzyzanowski; Costa (2018)

\subsection{Análise dos dados}

Os dados foram tabulados e submetidos ao teste de normalidade e posteriormente foi feito a análise de variância pelo teste F. Em seguida os dados foram submetidos ao teste de Scott Knott a 5\% de probabilidade de erro, com auxílio do software SISVAR (Ferreira, 2014).

\section{Resultados e Discussão}

Houve diferença estatística $(\mathrm{p}<0,05)$ entre os cultivares para todas as características avaliadas. Para a variável altura de plantas foram observados três grupos. Das oito variedades cultivadas no talhão Khatounian seis tiveram altura média de 126,51 centímetros; uma com altura de 100,00 centímetros e a menor observada na variedade BRS 391 foi de 72,45 centímetros. Para o diâmetro de caule também se observou três grupos: O maior diâmetro com 10,71 cm; o mediano com 9,15 $\mathrm{cm}$ e o menor diâmetro médio foi de $8,19 \mathrm{~cm}$. Para inserção da primeira vagem constatou-se quatro grupos distintos. No Khatounian onde estavam as oito cultivares as que tiveram maior peso de mil grãos foram: BRS 539 e BRS 166013 com peso médio de 160,73 g; bem como, a BRS 525 com 159 g cultivada no talhão Hahnemann (Tabela 2).

Na Figura 4 (a) são apresentados são apresentados os resultados médios para a população de plantas e o índice de acamamento das variedades cultivadas. A maior população de plantas foi observada nas variedades: DF 2353 e BRS 539 ambas cultivadas no talhão Hahnemann. 
Tabela 2: Resultado médio para altura de plantas, diâmetro de colmo, inserção da primeira vagem e peso de mil grãos para oitos variedades de soja cultivadas em sistema agroecológico.

\begin{tabular}{llcccc}
\hline Talhão & Cultivar & $\begin{array}{c}\text { Altura de plantas } \\
(\mathrm{cm})\end{array}$ & $\begin{array}{c}\text { Diâmetro } \\
\text { do caule } \\
(\mathrm{cm})\end{array}$ & $\begin{array}{c}\text { Inserção da } 1^{\circ} \text { Vagem } \\
(\mathrm{cm})\end{array}$ & $\begin{array}{c}\text { Peso de mil grãos } \\
(\mathrm{g})\end{array}$ \\
\hline \multirow{6}{*}{ Khatounian } & $9,21 \mathrm{~b}$ & $14,15 \mathrm{~b}$ & $160,00 \mathrm{a}$ \\
& BRS 525 & $122,41 \mathrm{a}$ & $7,97 \mathrm{c}$ & $13,53 \mathrm{~b}$ & $150,70 \mathrm{~b}$ \\
& DF 2353 & $100,00 \mathrm{~b}$ & $8,64 \mathrm{c}$ & $11,54 \mathrm{~b}$ & $163,90 \mathrm{a}$ \\
& BRS 539 & $127,76 \mathrm{a}$ & $10,51 \mathrm{a}$ & $9,50 \mathrm{c}$ & $149,50 \mathrm{~b}$ \\
& GE 02 & $126,10 \mathrm{a}$ & $9,29 \mathrm{~b}$ & $13,75 \mathrm{~b}$ & $158,30 \mathrm{a}$ \\
& BRS 16 6013 & $127,40 \mathrm{a}$ & $10,91 \mathrm{a}$ & $7,18 \mathrm{~d}$ & $150,90 \mathrm{~b}$ \\
& BRS 284 & $126,78 \mathrm{a}$ & $8,97 \mathrm{~b}$ & $16,29 \mathrm{a}$ & $145,20 \mathrm{~b}$ \\
& BRS 511 & $133,06 \mathrm{a}$ & $7,98 \mathrm{c}$ & $8,50 \mathrm{c}$ & $148,50 \mathrm{~b}$ \\
\hline \multirow{3}{*}{ Hahnemann } & BRS 391 & $72,45 \mathrm{c}$ & $8,59 \mathrm{c}$ & $8,90 \mathrm{c}$ & $159,00 \mathrm{a}$ \\
& BRS 525 & $93,91 \mathrm{~b}$ & $8,29 \mathrm{c}$ & $5,18 \mathrm{~d}$ & $146,80 \mathrm{~b}$ \\
\hline
\end{tabular}

Letras iguais minúscula na coluna não diferem entre si pelo teste de Scott-Knott.

Fonte: Autores.

Os índices de acamamento variaram de 1,0 a 4,9, sendo que 50\% das variedades avaliadas apresentaram índice de acamento igual ou menor que 1,6; sendo consideradas com baixo número de plantas acamadas. As maiores notas nesta variável foram observadas nas variedades a BRS 539 e BRS 511 com índice de 4,8 e 4,9 respectivamente. O acamamento afeta diretamente no desempenho das colhedoras, pois plantas acamadas significam perdas no rendimento de grãos, pela incapacidade do recolhimento dos grãos, além de poder ocasionar perdas de qualidade pelo contato direto com as vagens. Isso pode resultar em incidência de fungos e pragas (Shigihara e Hamawaki, 2005). O acamamento de plantas é influenciado não só pela ação dos ventos, mas ainda pelo tipo de solo e pelas condições de desenvolvimento da planta. Outro ponto a ser considerado refere-se à altura de planta. Normalmente, plantas mais altas poderão proporcionar maior índice de acamamento por apresentarem caules mais finos, ficando mais sujeitas ao tombamento pela ação dos ventos (Guimarães et al., 2008; Rocha et al., 2001), comportamento não observado neste estudo.

Observou-se diferenças significativas para a produtividade entre as variedades cultivadas (Figura 4 b). Elas se diferenciaram em três grupos: as mais produtivas, as medianas e as menos produtivas. As que obtiveram maiores produtividades foram: BRS 525 cultivada nos dois talhões e no talhão Kathounian a BRS 539, BRS 391 e a BR 166013 com produtividade média de $3178 \mathrm{~kg} \mathrm{ha}^{-1}$. O segundo grupo para produtividade foram: DF 2553 cultivada nos dois talhões e a BRS 284 no talhão Kathounian, com produtividade média de $2286 \mathrm{~kg} \mathrm{ha}^{-1}$. No terceiro grupo (menos produtivas) ficaram as variedades GE-02 e BRS 511, com produtividade média de $1673 \mathrm{~kg} \mathrm{ha}^{-1}$. Portanto, o primeiro grupo produziu 39\% e 89,93\% a mais que o segundo e terceiro grupo, respectivamente.

A produtividade nacional média da soja convencional foi de $3.517 \mathrm{~kg} \mathrm{ha}^{-1}$ (Embrapa, 2021); o que representa $10 \%$ a mais do que a obtida com as cultivares mais produtivas neste trabalho; isso demonstra que os manejos adotados estão sendo adequados, porém melhorias podem ser realizadas para aumentar a produtividade.

Esta produtividade foi bem maior da observada por Olson et al. (2014) em seis anos de cultivo de soja no estado de Illinois, USA. Os autores obtiveram uma produtividade média de $2.170 \mathrm{~kg} \mathrm{ha}^{-1}$. Enquanto, Ball et al. (2019) estudando diferentes manejos de plantas espontâneas em dois anos de cultivo de soja orgânica obteve uma produtividade média de 2.400 $\mathrm{kg} \mathrm{ha}^{-1}$. O que também foi observado por Sujii et al. (2002) no cultivo de soja orgânica no Distrito Federal, cuja produtividade média foi de $2.100 \mathrm{~kg} \mathrm{ha}^{-1}$. 
Constatou-se que a partir do estádio R2 iniciou a ocorrência do percevejo marrom tornando-se a praga mais importantes na fase de formação e desenvolvimento dos grãos. Mesmo com elevada ocorrência natural de parasitismo de ovos de percevejos, observados no período em que o monitoramento era realizado, e da adoção de armadilhas atrativas, a praga permaneceu acima do nível de controle ( 2 percevejos por pano de batida) após o estádio R4, demonstrando que outras alternativas de controle devem ser estudadas. Porém, em áreas convencionais, nesta mesma safra, também foram observadas altas populações de percevejos, mesmo após a aplicação de produtos químicos para o seu controle. Dessa forma, a população de percevejo e os danos observados na área apesar de serem elevados, poderiam ter sido maiores caso não houvesse os manejos adotados.

Figura 4: (a) População de soja por hectare e índice de acamamento; (b) Produtividade e ciclo das culturas.

(a)

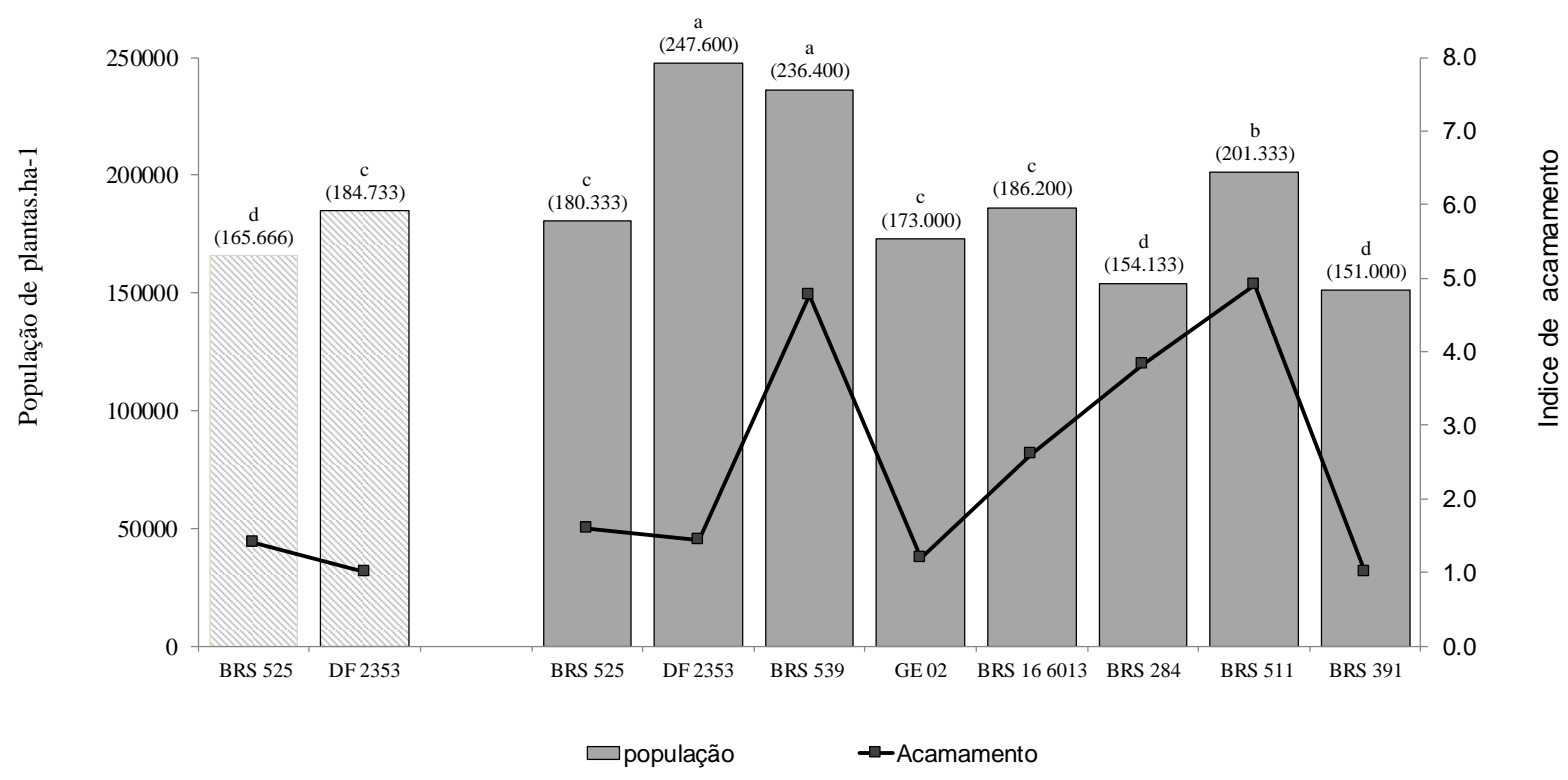

(b)

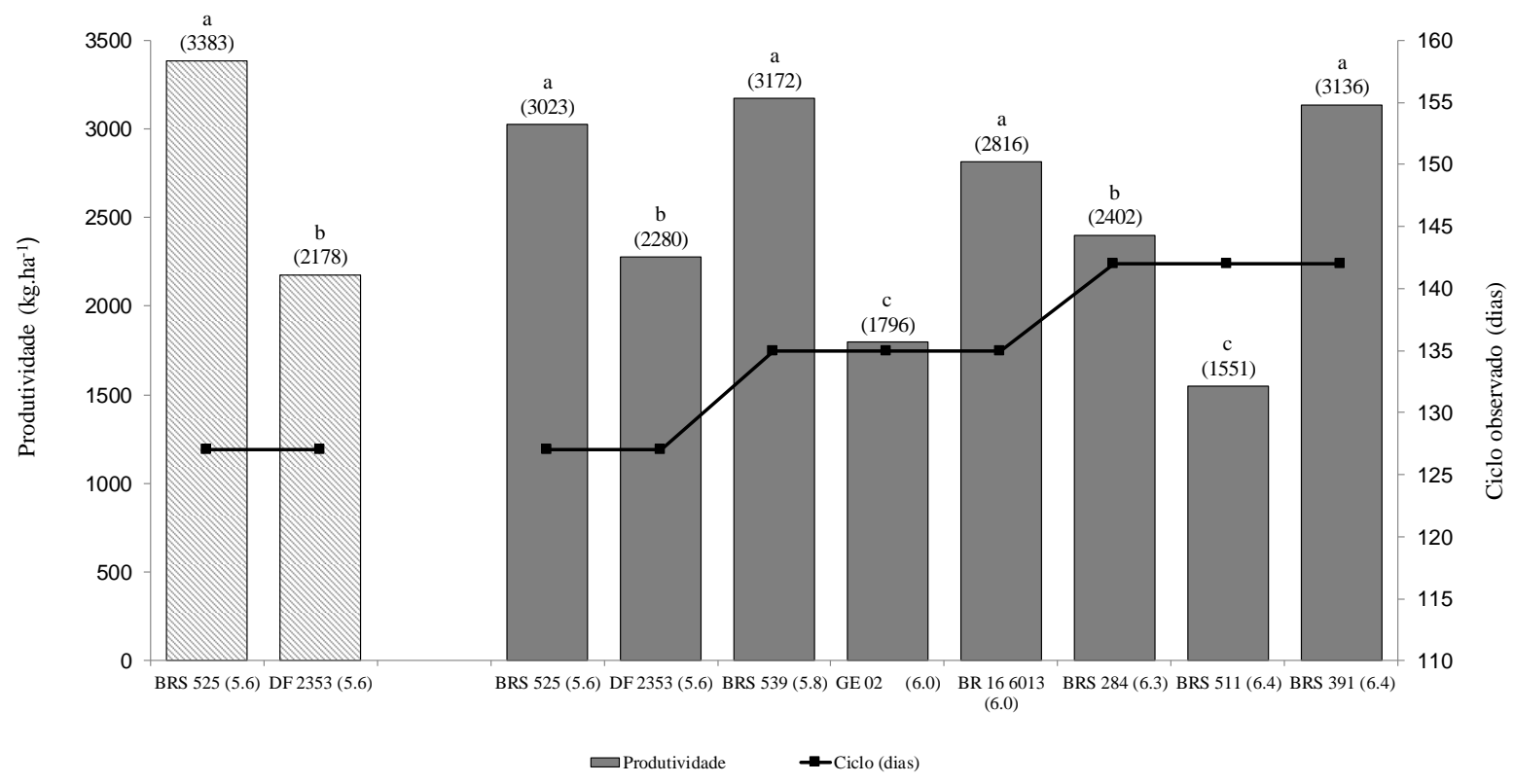

Fonte: Autores. 
Na Figura 5 são apresentados os danos causados por percevejos nos grãos de soja. As variedades foram agrupadas de acordo com ciclo de cada cultivar. Nas cultivares de ciclo precoce o número de indivíduos variou de 1,3 a 4,0 indivíduos, resultando em danos de 25 a 35\% no grão. Enquanto, nas variedades de ciclo tardio foram observados os maiores danos causados pelo percevejo, em torno de $65 \%$ das sementes avaliadas, nessas variedades a população de percevejos era de $13,7 \mathrm{e}$ 22,2 indivíduos no estádio R6 e R8, respectivamente.

Figura 5: Número de indivíduos por estádio da cultura e porcentagem de danos nos grãos por ciclo de variedades.

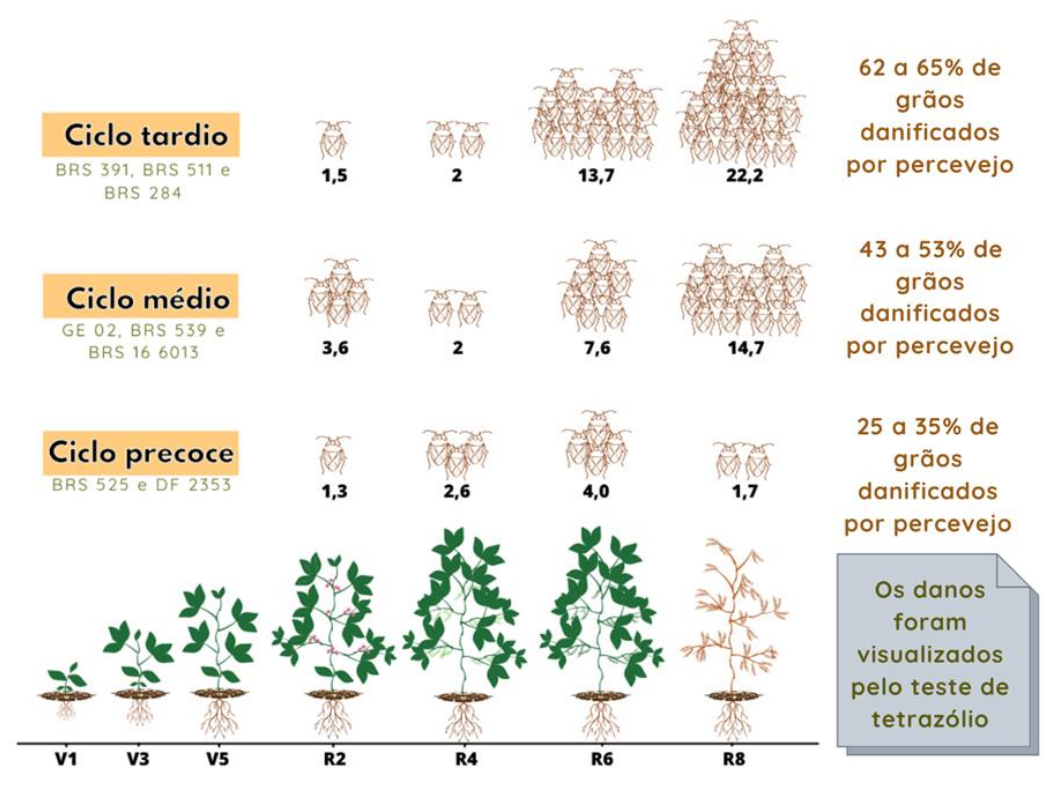

Fonte: Autores.

O ataque elevado de percevejo pode causar queda na produtividade, redução na qualidade do grão ou injetar toxinas causando deformações às plantas. Esses resultados demonstram que a utilização de cultivares precoces é alternativa para reduzir danos ocasionados pelo percevejo, principalmente pelo desenvolvimento mais rápido e colheita antecipada dessas cultivares, o que reduz a pressão de população nos períodos mais críticos da cultura.

Alguns trabalhos demonstram que a aplicação de sílica via foliar pode diminuir os danos causado pelo ataque do percevejo (Bussolaro et al. (2011); mas, Santo, et al. (2020) e Barbosa et al. (2020) não obtiveram redução no número de percevejos em soja com a aplicação foliar de silício.

\section{Conclusão}

$\checkmark$ Os resultados obtidos, são referentes a apenas a safra 2020/2021, e dependendo das condições climáticas, manejo realizado e histórico da área o comportamento dos cultivares pode ser diferente.

$\checkmark \quad$ Para a escolha do cultivar o produtor deve levar em consideração outras características agronômicas além da produtividade. Dentre elas o grupo de maturação (ciclo), região de adaptação (altitude), resistências a pragas em especial percevejos, tolerância doenças e ao acamamento.

$\checkmark$ Os resultados dessa safra evidenciam a importância do ajuste do grupo de maturação de acordo com a época de semeadura. Os cultivares precoces possuem menor capacidade de tolerar estresses hídrico. Entretanto, sofrem menos a incidência de percevejos. 
$\checkmark$ Os manejos adotados antes e durante a condução da cultura em ambos os talhões foram satisfatórios, necessitando apenas melhorias com relação ao manejo do percevejo marrom.

$\checkmark$ Trabalhos futuros deverão ser realizados para verificar se as variedades avaliadas neste ano terão o mesmo comportamento nos cultivos sucessivos e novas metodologias de controle de percevejos deverão ser avaliadas, buscando-se maior eficiência de seu controle.

\section{Agradecimentos}

A CAPES, MCTI, ITAIPU E GEBANA pelo apoio financeiro aos projetos realizados. A equipe de trabalho dos grupos de pesquisas: ACÚLEUS, GEMOP, GESA.

\section{Referências}

Aidar, H. \& Kluthcouski, J. Realidade versus sustentabilidade na produção do feijoeiro comum (2009. In: Kluthcouski, J.; Stone, L.F.; Aidar, H. Fundamentos para uma agricultura sustentável, com ênfase na cultura do feijoeiro. Santo Antônio de Goiás: Embrapa Arroz e Feijão, 23-33.

Avila, C. J., Vivan, L. M. \& Tomquelski, G. V. (2013). Ocorrência, aspectos biológicos, danos e estratégias de manejo de Helicoverpa armigera (Hübner) (Lepidoptera: Noctuidae) nos sistemas de produção agrícolas. Dourados: Embrapa Agropecuária Oeste, 12 p. (Embrapa Agropecuária Oeste. Circular técnica, 23).

Azadi, H., Schoonbeek, S., Mahmoudi, H., Derudder, B., De Maeyer, P. \& Witlox, F. (2011) Organic agriculture and sustainable food production system: main potentials. Agriculture, Ecosystems and Environment, 144, 92-94. 10.1016/j.agee.2011.08.001

Barbosa, R. T., Torres, F. E., Zanuncio, A. dos S., Teodoro, P. E., Mendonça, G. G. de \& Santo, F. do E. (2020). Flutuação populacional de percevejos na cultura da soja com aplicação de silício na região do ecótono cerrado-pantanal. Research, Society and Development, 9(7), e582973824.

Ball, M. G., Caldwell, B. A., DiTommaso A., Drinkwater, L. E., Mohler, C. L., Smith, R. G. \& Ryan, M. R. (2019) Weed community structure and soybean yields in a long-term organic cropping systems experiment. Weed Science, 67: 673-681.

Brasil. Ministério da Agricultura, Pecuária e Abastecimento (2009). Regras para Análise de Sementes. Mapa/ACS, 395p.

Brighenti, A. M. \& Brighenti, D. M. (2009). Controle de plantas daninhas em cultivos orgânicos de soja por meio de descarga elétrica. Ciência Rural, 39(8), 2315-2319.

Bussolaro, I., Zelin, E., \& Simoneti, A. (2011). Aplicação de silício no controle de percevejos e produtividade da soja. Cultivando o Saber,4(3), 9-19.

Caviglione, J. H., Kiihl, L. R. B. \& Caramori, P. H., Oliveira, D. Cartas climáticas do Paraná. Londrina, IAPAR, 2000. CD ROM

Corrêa-Ferreira, B. S. (2012). Amostragem de pragas da soja. Soja: Manejo Integrado de Insetos e outros Artrópodes-Praga. Embrapa, Brasilia, DF, 631-672.

Darolt, M.R. (2000). As dimensões da sustentabilidade: um estudo da agricultura orgânica na região metropolitana de Curitiba - PR. 2000.310 f. Tese (Doutorado em Meio Ambiente e Desenvolvimento) - Universidade Federal do Paraná, Curitiba.

Deser, Departamento de Estudos Socio-econômicos Rurais. A cadeia produtiva da soja orgânica (2008). <http://www.deser.org.br/publicacoes/15_Estudo\%20Explorat\%F3rio\%20da\%20Soja\%20Org\%E2nica.pdf>.

Embrapa, Empresa Brasileira de Pesquisa Agropecuária (2015). Soja orgânica. <https://www.embrapa.br/soja/cultivos/soja1/soja-organica>.

Embrapa, Empresa Brasileira de Pesquisa Agropecuária (2021). Soja em números. https://www.embrapa.br/en/soja/cultivos/soja1/dados-economicos

Embrapa, Empresa Brasileira de Pesquisa Agropecuária (2014). Captura de Percevejos Armadilha com urina bovina. https://ainfo.cnptia.embrapa.br/digital/bitstream/item/97917/1/folder-armadilha-copy.pdf.

Ferreira-Correa, B. S., Krzyanowski, F. C. \& Minami, C. A. (2009). Percevejos e a qualidade de sementes de soja - séries sementes. Embrapa (Circular Técnica), 16p. https://www.agrolink.com.br/downloads/percevejos\%20e\%20a\%20soja.pdf

Ferreira, D. F. Sisvar: um guia dos seus procedimentos de comparações múltiplas Bootstrap. Ciência e Agrotecnologia, 38(2).

Fontanetti, A. et al. (2006). Produção de milho orgânico no sistema de plantio direto. Informativo.Agropecuário, 27(233), 127-136.

França Neto, J. B., \& Krzyzanowski, F.C. (2018). Metodologia do teste de tetrazólio em sementes de soja. Embrapa Soja, $406,108$.

Guimarães, F.S. et al. (2008). Cultivares de soja [Glycine max (L.) Merrill] para cultivo de verão na região de Lavras-MG. Ciência e Agrotecnologia, 32(04), 1099-1106.

Hiroki, U. \& Ashok, K.M. (2012). Organic farmers or conventional farmes: Where's money? Ecological Economics, 78, 55-62 
Inagaki, M. N., Junqueira, C. P. \& Bellon, P. P. (2018). Desafios da produção de soja orgânica como determinante à implantação de seu cultivo para fins comerciais na região do oeste do Paraná. Revista Gestão \& Sustentabilidade Ambiental. Florianópolis, 7(1), 682-699. 10.19177/rgsa.v7e12018682-699.

Kenneth, O., Stephen, A.E. \& James, M.L. (2014). Long-term Effects of cover crops on crop yields, soil organic carbon stocks and sequestration, Open Journal of Soil Science, 4(8), 9. 10.4236/ojss.2014.48030

McBride, W. \& Greene, C. (2009). The profitability of organic soybean production. Renewable Agriculture and Food Systems, 24(4), 276-284. https://doi.org/10.1017/S1742170509990147

Pereira, L.B., Arf, O., Santos, N.C.B. dos, Oliveira, A.E.Z. \& Komuro, L.K. (2015). Manejo da adubação na cultura do feijão em sistema de produção orgânico. Pesquisa Agropecuária Tropical, 45(1), 29-38. www.agro.ufg.br/pat - Pesquisa Agropecuária Tropical, 45(1), 29-38.

Olson, K., Ebelhar, S. \& Lang, J. (2014) Long-Term Effects of Cover Crops on Crop Yields, Soil Organic Carbon Stocks and Sequestration. Open Journal of Soil Science, 4, 284-292. 10.4236/ojss.2014.48030.

Rocha, R.N.C. et al. (2001). Comportamento de cultivares de soja em diferentes populações de plantas, em Gurupi, Tocantins. Revista Ceres, 48(279), 529537.

Sacco, D., Moretti, B., Monaco, S. \& Grignani, C. (2015). Six-year transition from conventional to organic farming: effects on crop production and soil quality. European Journal of Agronomy, 69, 10-20. 10.1016/j.eja.2015.05.002.

Santos, R. D., Lemos, R. C., Santos, H. G., Ker, J. C. \& Anjos, L. H. C. Manual de descrição e coleta de solo no campo. 7.ed. Viçosa: SBCS, 2015. 92p.

Santo, F. do E., Torres, F. E., Zanuncio, A. dos S., Teodoro, P. E., Mendonça, G. G. de \& Barbosa, R. T. (2020). Efeito do silício ao ataque de lagartas e percevejos em cultivares de soja no ecótono cerrado/pantanal. Research, Society and Development,9(7), e269973821, 2020.

Simonetti, D. \& Perondi, M. A. (2019). A Crise da Soja Orgânica. Revista Cronos, 19(1), 84-103

Sujii, E. R., Pires, C. S. S., Schmidt, F. G. V., Armando, M. S., Borges, M. M., Carneiro, R. G. \& Valle, J. C. V. (2002). Controle biológico de insetos-praga na soja orgânica do distrito federal. Cadernos de Ciência \& Tecnologia, 19(2), 299-312

Shigihara, D \& Hamawaki, O. T. (.2005) Seleção de Genótipos para Juvenilidade em Progênies de soja (Glycine max (L.) Merrill). Bioscience Journal. 01-26.

Uematsu, H., \& Mishra, A. K (2012). Organic farmers or conventional farmers: Where's the money? Ecological Economics, 8, 55-62

Zorzzi, I. C., Cruz, M. P. da, Dalacosta, N. L., Bruzamarello, J., Ghedin, Álvaro L. \& Mazaro, S. M. (2021). Alternative products on the control of asian rust soybean. Research, Society and Development, 10(1). e1110110667 10.33448/rsd-v10i1.10667 